\title{
Influence of shade, curing mode, and aging on the color stability of resin cements
}

\author{
Janes Francio Pissaia ${ }^{1}$, Gisele Maria Correr ${ }^{1}$, Carla Castiglia Gonzaga ${ }^{1}$, Leonardo Fernandes da Cunha ${ }^{1}$
}

${ }^{1}$ Universidade Positivo - UP, Dental School, Department of Operative Dentistry, Curitiba, PR, Brazil

\begin{abstract}
The color stability of resin cements is essential for aesthetic restorations. Aim: To evaluate the influence of shade and aging time on the color stability of two light-cured and two dual-cured resin cements. Methods: The CIE-Lab color parameters $(n=6)$ were measured immediately after sample preparation and at 7,30 and 90 days of aging in distilled water. The color difference $(\Delta \mathrm{E})$ was calculated and then analyzed by three-way ANOVA for repeated measures and Tukey's HSD test $(\alpha=0.05)$. Results: $\Delta E$ was higher for transparent resin colors, followed by dark and light colors. The mean values of $\Delta \mathrm{E}$ were lower for both light-cured resin cements compared to the dual-cured cements. As the aging time increased, $\Delta E$ values increased. Conclusions: The light-cured resin cements showed greater color stability. The lighter shades of luting were more likely to display a greater color change.
\end{abstract}

Keywords: aging; color; dental cements; esthetics; dental materials.

\section{Introduction}

Resin-based cements have been extensively applied for aesthetic restorations with translucent material, like dental ceramic veneers ${ }^{1-2}$. It is essential that the color of the aesthetic materials remains stable over a long period in the oral environment ${ }^{3-4}$. Previous studies have described color changes occurring in direct dental composites ${ }^{5-9}$. However, as Koishi et al. have remarked ${ }^{4}$, the color stability of luting composites requires careful analysis. Luting composites and direct composite resins have similar compositions (in terms of the polymer matrix and fillers), and therefore the color stability of luting composites may be affected by chemical components.

Inorganic oxide additives are typically used to create material shades that match the color of the tooth or other restorative materials used with resin-based cements ${ }^{10}$. Depending on the manufacturer, one or multiple shades may be applied. Uchida et al. reported that the discoloration of a direct composite resin is influenced by shade selection ${ }^{8}$ : the lighter the shade, the higher the tendency for discoloration. As direct composite materials and luting cements have similar chemical components

Received for publication: November 18, 2015 Accepted: December 11, 2015

Correspondence to: Janes Francio Pissaia Graduate Program in Dentistry,

Universidade Positivo, Curitiba, PR, Brazil Rua Professor Pedro Viriato Parigot de Souza 5300 - Curitiba - PR - CEP: 81280-330

Phone: 554699301204

E-mail: janespissaia@hotmail.com (organic matrix and fillers), the color stability of resin-based cements may also be affected by shade selection.

Resin-based cements may be classified based on whether they are chemically cured, light-cured or dual-cured materials ${ }^{11}$. Light-cured resin cements present increased working time and the removal of excesses of material is easier than for chemically cured materials. On the other hand, dual-cured luting materials contain compounds for both chemical and light curing, and consequentially these materials possess beneficial traits from both polymerization systems. The combination of curing systems used with dual-cured resin cements is reported to reduce the number 
of remaining double bonds, which improves the degree of conversion $^{12}$. As the color of resin-based materials is related to the degree of conversion ${ }^{13-14}$, dual-cured luting materials should show better color stability than the light-cured resin cements.

In the case of aesthetic restoration materials, such as ceramic veneers, the color stability of the resin-based cement employed for the cementation procedure may be as important for the long-term clinical success of the restoration as the mechanical properties of veneering material. When ultrathin ceramic veneers are used, the color of the resin-based cement plays a major role.

The aim of this study was to evaluate the color stability of four different luting cements with variations in curing mode, shade and aging time. The experimental design tested three null hypotheses: that there might be no difference in color stability between the evaluated shades, that the method of polymerization might not influence the color stability, and that aging in water might induce no changes in color.

\section{Material and methods}

Three shades (transparent, clear, and dark) of each four resin-based cements (Rely X Veneer 3M/ESPE, Germany, light-cured; Choice 2 Bisco, USA, light-cured; Variolink II Ivoclar-Vivadent, Germany, dual-cured; and AllCem FGM, Brazil, dual-cured) were evaluated in this study. The key attributes of each material are in Table 1.

All specimens were prepared in controlled relative humidity $(55 \pm 5 \%)$ and temperature $\left(23 \pm 1{ }^{\circ} \mathrm{C}\right)$. Each luting composite was mixed in accordance with the manufacturer's instructions. Six disk specimens, $5 \mathrm{~mm}$ diameter and $1 \mathrm{~mm}$ thick, were prepared for each shade and material. Each specimen was made by inserting the resin-based cement into a Teflon mold ring and pressed between two 1-mm-thick glass slides under finger pressure. All samples were continuously light-cured with a LED light source (Dental Woodpecker LED, $1200 \mathrm{~mW} / \mathrm{cm}^{2}$ ), according to the manufacturer's instructions (Rely X Veneer 3M/ESPE - 30 s,; Choice 2 Bisco - 40 s; Variolink II Ivoclar-Vivadent - 40 $\mathrm{s}$; and AllCem FGM - $40 \mathrm{~s}$ ), by placing the light tip on the glass slide covering the entire area of each specimen.

Specimens were stored in dark canisters containing distilled water at $37{ }^{\circ} \mathrm{C}$ for $24 \mathrm{~h}$. The color of each specimen was first determined after $24 \mathrm{~h}$, and this was defined as the baseline color evaluation. The color measurements were performed with an EasyShade spectrophotometer (Vita Zahnfabrik, Bad Säckingen, Germany) according to the CIELab (Commision Internationale de l'Eclairage) $\mathrm{L}^{*}, \mathrm{a}^{*}, \mathrm{~b}^{*}$ coordinates. The CIE $\mathrm{L}^{*}$ parameter corresponds to the degree of light and darkness, whereas $a^{*}$ and $b^{*}$ coordinates correspond to red or green $\left(+a^{*}=\right.$ red, $-a^{*}=$ green $)$ and yellow or blue $\left(+b^{*}=\right.$ yellow, $-b^{*}=$ blue $)$, respectively. The specimens were then stored in dark canisters containing distilled water at $37{ }^{\circ} \mathrm{C}$, and the color values were again measured after 7, 30 and 90 days. The specimens were placed on a white background during the measurement to prevent potential absorption effects on any of the measured color parameters. The mean of three measurements on each sample was used to represent the average values of the color parameters of each sample and these average values were used for the overall data analysis. The CIE-lab coordinates were used to calculate the color difference $(\Delta \mathrm{E})$ between the baseline color measurement and the aged specimens. Before each color measurement, the immersed specimens were dried with absorbent paper. The $\Delta \mathrm{E}$ for each experimental time was calculated using the following equation:

$$
\Delta \mathrm{E}=\left[\left(\Delta \mathrm{L}^{*}\right)^{2}+\left(\Delta \mathrm{a}^{*}\right)^{2}+\left(\Delta \mathrm{b}^{*}\right)^{2}\right]^{1 / 2}
$$

where $\Delta \mathrm{L}^{*}, \Delta \mathrm{a}^{*}$, and $\Delta \mathrm{b}^{*}$ are the differences in the respective values before and after aging. The $\Delta \mathrm{E}$ values were analyzed by three-way ANOVA for repeated measures and Tukey's HSD test $(\alpha=0.05)$.

\section{Results}

The mean values of $\Delta \mathrm{E}$ for the three different variables in this study, along with standard deviations, are in Tables 2-4. Significant effects of curing mode, shade and aging time on the color stability were observed. As shown in the results of resin shade comparison in Table 2, $\Delta \mathrm{E}$ values were the highest for translucent resins $(p=0.000009)$, and lowest for clear and dark resins. There were no significant differences

Table 1. Materials used in the present study.

\begin{tabular}{|c|c|c|c|c|}
\hline Material & $\begin{array}{l}\text { Curing } \\
\text { Mode }\end{array}$ & $\begin{array}{l}\text { Color } \\
\text { Transparent }\end{array}$ & $\begin{array}{l}\text { Color } \\
\text { Clear }\end{array}$ & $\begin{array}{l}\text { Color } \\
\text { Dark }\end{array}$ \\
\hline $\begin{array}{l}\text { Choice } 2 \\
\text { Bisco }\end{array}$ & Light-cured & Translucent & $\mathrm{A} 1$ & A2 \\
\hline $\begin{array}{l}\text { Rely X Veneer } \\
\text { 3M/ ESPE }\end{array}$ & Light-cured & Translucent & $\mathrm{A} 1$ & A3 \\
\hline $\begin{array}{l}\text { Variolink II } \\
\text { Ivoclar-Vivadent }\end{array}$ & Dual-cured & Transparent & $\begin{array}{l}\text { Light Yellow-A1 } \\
\text { White (110/A1) }\end{array}$ & $\begin{array}{l}\text { Opaque Yellow-A3Yellow/ } \\
\text { Universal (210/A3) }\end{array}$ \\
\hline $\begin{array}{l}\text { AllCem } \\
\text { FGM }\end{array}$ & Dual-cured & Transparent & A1 & A3 \\
\hline
\end{tabular}


between clear and dark shades of the tested materials.

Comparing the four resins in terms of the type of curing, the dual-cured AllCem cement had higher $\Delta \mathrm{E}$ values when compared to light-cured materials (Table 3$)(p=0.000016)$. No significant difference was found between the dual-cured cement Variolink II and the light-cured materials.

When aging time was considered, the mean values of $\Delta \mathrm{E}$ increased with time from 7 to 30 to 90 days (Table 4, $\mathrm{p}=0.000000)$.

Table 2. Mean $\Delta \mathrm{E}$ values and corresponding standard deviations (SDs) between different shades of resin-based cements.

\begin{tabular}{lll}
\hline Color & Mean & SD \\
Clear & $3.12^{\mathrm{A}^{*}}$ & 0.74 \\
Dark & $3.25^{\mathrm{A}}$ & 1.13 \\
Transparent & $4.41^{\mathrm{B}}$ & 1.04 \\
\hline
\end{tabular}

*different letters indicate statistically significant difference between group

Table 3. Mean $\Delta \mathrm{E}$ values and corresponding $\mathrm{SDs}$ for the tested four resin-based cements.

\begin{tabular}{lll}
\hline Material & Mean & SD \\
Choice 2 & $2.79^{\mathrm{A}^{*}}$ & 0.71 \\
Rely X Veneer & $3.49^{\mathrm{A}}$ & 0.77 \\
Variolink II & $3.60^{\mathrm{A}}$ & 1.42 \\
AllCem & $4.48^{\mathrm{B}}$ & 0.99 \\
\hline
\end{tabular}

*different letters indicate statistically significant difference between group

Table 4. Mean $\Delta \mathrm{E}$ values and corresponding $\mathrm{SDs}$ for different aging times.

\begin{tabular}{lll}
\hline$\Delta E$ (days) & Mean & $S D$ \\
7 & $2.79^{A^{*}}$ & 0.51 \\
30 & $3.73^{\mathrm{B}}$ & 1.01 \\
90 & $4.25^{\mathrm{C}}$ & 1.40 \\
\hline
\end{tabular}

*different letters indicate statistically significant difference between group

\section{Discussion}

All three evaluated null hypotheses in the present study were rejected: the experimental results revealed that the color stability varied among resin shades, curing methods and specimen aging times.

Storage in water is frequently used for in vitro aging of restorative composite materials. In this study, water exposure for longer periods of time caused increased changes in the CIE color space coordinates of the composites (Table 4). It is well known that water absorbed in the polymer matrix causes filler matrix debonding and hydrolytic degradation of the filler ${ }^{15-16}$, and it also could change the refractive index of the material ${ }^{4}$. Therefore, the increase of the $\Delta \mathrm{E}$ values might be affected by water sorption in the used luting composites. The $\Delta \mathrm{L}$ values increased as the immersion period increased, suggesting that the color of a luting composite tends to darken over long-term clinical use ${ }^{4}$. Other researchers have demonstrated that composite materials undergo discoloration by exposure to sources like UV light, visible light and/or heating ${ }^{6,17}$.

In prosthetic composites, Ruyer et al. reported that color changes with $\Delta \mathrm{E}$ values lower than 3.3 were acceptable ${ }^{18}$; Turgut et al. reported that $\Delta \mathrm{E}$ values lower than 3.5 were also acceptable ${ }^{19}$. After aging, all specimens showed changes in $\ddot{A} E$ values, but almost all the color differences had acceptable values. However, the mean $\Delta \mathrm{E}$ values for transparent resin shades and for the dual-curable resin cement were above the acceptable. After 30 and 90 days of laboratory aging, $\Delta \mathrm{E}$ values were also higher than acceptable. These results are related to the used method, because the uncovered resin disks used in this study, similar to those used in previous reported ageing tests ${ }^{20-22}$, have increased exposure to potentially damaging environmental factors.

Different number of samples are used for this kind of research; for example, Uchida et al. 1998 used 3 samples per group $^{8}$. On the other hand, five specimens were prepared for each group by Koishi et al. 2002 ${ }^{4}$, Lu and Powers 2004 ${ }^{23}$, Furuse et al. $2008^{6}$. In the present study, six samples were enough to provide statistically significant difference, thus no more samples were fabricated.

The effect of shades on the color stability of luting composites was statistically significant. The relative values of $\mathrm{DE}^{*} \mathrm{ab}$ were dark $=$ clear $<$ transparent. This suggests that higher color degradation occurred on the colorimetrically lighter and less chromatic shades in the studied composite systems. It was previously shown that lighter shades yield more visible color changes than dark shades in a semi quantitative comparison for direct composite resins ${ }^{8}$. According to Uchida et $a .^{8}$, the higher discoloration associated with lighter shades may result from environmental breakdown of the polymer. This breakdown leads to the release of monomers and causes the cured resin color to shift to the color of the monomers. Alternatively, environmental damage can cause a color change by affecting the retention and/or stability of pigments and other additives in the polymer formulations. The aesthetic performance of porcelain laminates can be affected by the color of the resin cements used to bond them to teeth ${ }^{22}$. The current results indicate that lighter resin cements presented significantly more color change after aging.

Both the light-cured and the dual-cured cements presented color changes. Degradation of residual amines and oxidation of residual unreacted carbon-carbon double bonds result in the formation of yellowing compounds in resinbased materials ${ }^{23}$. In the present study, the $\Delta \mathrm{E}$ values for dual-cured specimens were significantly higher than those for respective light-cured specimens. These results are in agreement with Brauer, who reported that veneer luting cement composites had better color stability when compared with the auto-cured materials containing tertiary aromatic amine accelerators ${ }^{17}$. Aromatic tertiary amines used in selfcured resins are more likely to oxidize than the aliphatic amines used in light-cured materials; therefore, light-cured cements are expected to have more color stability ${ }^{23}$. Factors such as monomer composition and filler content might also 
influence the color stability of luting composites ${ }^{4}$. This could explain the different color stability values between the two dual-cured resin cements tested in this study.

Many materials with different color and composition are commercially available. Further studies are required to evaluate color changes of resin luting cements and factors related to them in different situations, in order to improve long-term aesthetic results and help the dentists to have a better understanding of this issue ${ }^{24-26}$.

Within the limitations of this in vitro study, the following conclusions were drawn: the translucent shade materials exhibited higher $\Delta \mathrm{E}$ changes; the light-cured luting composite resin showed lower $\Delta \mathrm{E}$ values than the dual cured materials; the $\Delta \mathrm{E}$ values were influenced by the time of immersion period.

\section{References}

1. Oei JD, Mishriky M, Barghi N, Rawls HR, Cardenas HL, Aguirre R, et al. Development of a low-color, color stable, dual cure dental resin. Dent Mater. 2013; 29: 405-12.

2. Salameh Z, Tehini G, Ziadeh N, Ragab HA, Berberi A, Aboushelib MN. Influence of ceramic color and translucency on shade match of CAD/ CAM porcelain veneers. Int J Esthet Dent. 2014; 9: 90-7.

3. Turgut $\mathrm{S}$, Bagis $\mathrm{B}$, Turkaslan SS, Bagis $\mathrm{YH}$. Effect of ultraviolet aging on translucency of resin-cemented ceramic veneers: an in vitro study. J Prosthodont. 2014; 23: 39-44.

4. Koishi $\mathrm{Y}$, Tanoue N, Atsuta M, Matsumura $\mathrm{H}$. Influence of visible-light exposure on colour stability of current dual-curable luting composites. J Oral Rehabil. 2002; 29: 387-93.

5. Berber A, Cakir FY, Baseren M, Gurgan S. Effect of different polishing systems and drinks on the color stability of resin composite. J Contemp Dent Pract. 2013; 14: 662-7.

6. Furuse AY, Gordon K, Rodrigues FP, Silikas N, Watts DC. Colourstability and gloss-retention of silorane and dimethacrylate composites with accelerated aging. J Dent. 2008; 36: 945-52.

7. Reddy PS, Tejaswi KL, Shetty S, Annapoorna BM, Pujari SC, Thippeswamy HM. Effects of commonly consumed beverages on surface roughness and color stability of the nano, microhybrid and hybrid composite resins: an in vitro study. J Contemp Dent Pract. 2013; 14: 718-23.

8. Uchida $\mathrm{H}$, Vaidyanathan J, Viswanadhan T, Vaidyanathan TK. Color stability of dental composites as a function of shade. J Prosthet Dent. 1998; 79: 372-7.

9. Usumez A, Ozturk N, Ozturk B. Two-year color changes of light-cured composites: influence of different light-curing units. Oper Dent. 2005; 30 : 655-60.

10. Anusavice K. Phillips' science of dental materials, 12th ed. Saint Louis: Saunders; 2012.

11. Krämer N, Lohbauer U, Frankenberger R. Adhesive luting of indirect restorations. Am J Dent. 2000; 13(Spec N.): 60D-76D.

12. PeutzfeldtA. Dual-cure resin cements: in vitro wear and effect of quantity of remaining double bonds, filler volume, and light curing. Acta Odontol Scand. 1995; 53: 29-34.

13. Furuse AY, Mondelli J, Watts DC. Network structures of Bis-GMA/ TEGDMA resins differ in DC, shrinkage-strain, hardness and optical properties as a function of reducing agent. Dent Mater. 2011; 27: 497-506.

14. Imazato S, Tarumi H, Kobayashi K, Hiraguri H, Oda K, Tsuchitani Y. Relationship between the degree of conversion and internal discoloration of light-activated composite. Dent Mater. 1995; 14: 23-30.

15. Ferracane JL, Berge HX, Condon JR. In vitro aging of dental composites in water-effect of degree of conversion, filler volume, and filler/matrix coupling. J Biomed Mater Res. 1998; 42: 465-72.
16. Söderholm KJ, Zigan M, Ragan M, Fischlschweiger W, Bergman M. Hydrolytic degradation of dental composites. JDent Res. 1984; 63: 1248-54.

17. Brauer GM. Color changes of composites on exposure to various energy sources. Dent Mater. 1988; 4: 55-9.

18. Ruyter IE, Nilner K, Moller B. Color stability of dental composite resin materials for crown and bridge veneers. Dent Mater. 1987; 3: 246-51.

19. Turgut S. Bagis B. Colour stability of laminate veneers: an in vitro study. J Dent. 2011; 39 Suppl 3: e57-64

20. Gürdal P, Akdeniz BG, Hakan Sen B. The effects of mouthrinses on microhardness and colour stability of aesthetic restorative materials. J Oral Rehabil. 2002; 29: 895-901.

21. Janda R, Roulet JF, Latta M, Steffin G, Rüttermann S. Color stability of resin-based filling materials after aging when cured with plasma or halogen light. Eur J Oral Sci. 2005; 113: 251-7.

22. Alqahtani MQ, Aljurais RM, Alshaafi MM. The effects of different shades of resin luting cement on the color of ceramic veneers. Dent Mater J. 2012; 31: 354-61.

23. Lu H, Powers JM. Color stability of resin cements after accelerated aging. Am J Dent. 2004; 17: 354-8.

24. Mendes AP, Barceleiro MO, Reis RS, Bonato LL, Dias KR. Changes in surface roughness and color stability of two composites caused by different bleaching agents. Braz Dent J. 2012; 23: 659-66.

25. Pires-de-Souza Fde C, Garcia Lda F, Hamida HM, Casemiro LA. Color stability of composites subjected to accelerated aging after curing using either a halogen or a light emitting diode source. Braz Dent J. 2007; 18 : 119-23.

26. Almeida JR, Schmitt GU, Kaizer MR, Boscato N, Moraes RR. Resinbased luting agents and color stability of bonded ceramic veneers. J Prosthet Dent. 2015; 114: 272-7. 